\title{
Non-communicable diseases risk factors among government school teachers in Jodhpur, Rajasthan
}

\author{
Vibha Joshi ${ }^{1}$, Nitin Kumar Joshi ${ }^{2}$, Praveen Suthar ${ }^{3}$, Yogesh Kumar Jain ${ }^{4}$ \\ ${ }^{1,3,4}$ Department of Public Health, Lachoo Memorial College of science and Technology, Jodhpur, Rajasthan, India \\ ${ }^{2}$ School of Public Health, All India Institute of Medical Sciences, Jodhpur, Rajasthan, India
}

\section{Article Info \\ Article history: \\ Received Feb 19, 2021 \\ Revised Aug 12, 2021 \\ Accepted Aug 26, 2021}

\section{Keywords:}

Health behavior

Life change events

Non-communicable diseases

Risk factors

Physical fitness

School teachers

\begin{abstract}
Non-communicable diseases (NCDs) are considered as life-style diseases. School teachers' behavior in this context could be transmitted to students that may act as determining factor of prevention for NCDs at primordial level. Aim of this study is to assess the prevalence of risk factors among teachers and their practices with respect to common NCDs. A cross-sectional study was conducted in Jodhpur among 394 government school teachers. Questionnaire was adopted from WHO STEPS tool and responses were documented which included socio-demographic details, anthropometric measurements and risk factors including diet, hours of physical activity, smoking and alcohol intake. Mean age of participants was 43 years out of which $23 \%$ were found to be having blood pressure more than $140 / 90 \mathrm{~mm}$ of $\mathrm{Hg}$ at the time of interview. $4.8 \%$ consumed alcohol and $1.5 \%$ was smokers. Mean body mass index (BMI) was found to be 25.4 while only $13 \%$ had their cholesterol checked post 35 years of age. The $23.6 \%$ had knowledge of reducing fat by using the right type of cooking oil, $35.7 \%$ were engaged in any daily physical activity and $76 \%$ knew that excess salt was not good for health. This survey assessed baseline levels by identifying the overall prevalence and associated risk factors that provided first step towards initiating surveillance for NCDs among school teachers in Jodhpur, Rajasthan, whilst delivering the necessary information concerning with developing a suitable framework for determining priorities over intervention.
\end{abstract}

This is an open access article under the CC BY-SA license.

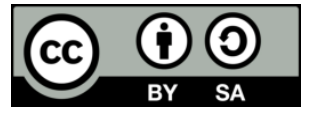

\section{Corresponding Author:}

Nitin Kumar Joshi

School of Public Health

All India Institute of Medical Sciences

B-110, Krishna Nagar, Pali Road, Basni 1st Jodhpur, Rajasthan 342005, India

Email: drjoshinitin30@gmail.com

\section{INTRODUCTION}

As per the WHO estimates, non-communicable diseases (NCDs) account for over 5.87 million total deaths in India (constituting roughly $60 \%$ of the total deaths) [1], [2]. NCDs prevalence estimated in Rajasthan with a self-reported morbidity has significantly increased from the three consecutive representation of National Sample Survey (1995, 2004 and 2014) especially with regards to the cardiovascular diseases (CVDs). The self-reporting has doubled indicating that the increase in prevalence from 1 to 2 cases per 1,000 population; while the estimates from NCDs in combination showed a gradual increase from about 3 to 20 cases within a net population of a 1,000 [1], [3].

It is pivotal for many governmental organizations, institutions and NGOs to impart awareness programs concerning improvement in the lifestyle of the public due to lack of awareness alongside insufficient or poor accessibility of health-care, especially in rural and semi-rural areas [4]. The risk factors 
for numerous NCD based conditions are being shared and their overall likelihood and the co-occurrence was also reported high. Thus, studies on single risk factors and the prevalence on behalf of individual risk factors miss complex interaction among the risk factors. For a better understanding of risk profiles of a population, the whole set of risk factors should be considered. Hence, there is a need for approaches that consider common risk factors together to describe risk profile of the population [5].

One of the jobs in which school instructors are subjected to psychological and workplace stress is teaching [6]. Teachers serve as role models for pupils, and kids pay close attention to their behaviour and lifestyle [7]. Moreover, if the school teachers have proper awareness of risk factors and are able to take control over determinants of NCDs, only than this positive role modelling may be transmitted to the students which will further help to prevent NCDs at primordial level [8].

The study emphasises a detailed assessment of the prevalence of risk factors among teachers, identifying the underlying risk factors associated with NCDs, assessing the underlying prevalence in the risk factors with regards to teachers and in determining their overall knowledge, perception and their practices with respect to common NCDs like hypertension, diabetes and obesity. Hence profiles pertaining to Jodhpur district in Rajasthan, India was subjected for the study. The study population involving government school teachers in and around the district were screened for NCDs and were further subjected to surveying.

\section{RESEARCH METHOD}

\subsection{Study setting: sample size and sampling}

A cross sectional study was conducted among 394 teachers from 16 schools of Jodhpur over a study period of six months from May to October, 2019. The sample size was calculated using the formula or calculation of sample size for cross sectional studies, i.e., $n=(Z) 2 P(P-1) / e 2$ where $n$ is sample size, $Z$ is level of confidence (1.96), P is baseline level of indicators (50), e is margin of error (5) [9]. Questionnaire adopted from WHO STEPwise instrument was utilized for collecting information regarding risk factors for NCDs including diet, hours of physical activity smoking, alcohol intake and physical measurements like BMI, waist circumference and blood pressure [9], [10]. The questionnaire was translated and pre-tested.

Educational level, generally graded as literates was not regarded in this case as participants were government teachers and professionals. The monthly household income was measured as a categorical variable. To gather information on physical activity, the information was gathered on three broad domains i.e., physical activity at work, transport-related physical activity, and leisure-time physical activity.

\subsection{Measurement}

Survey was conducted by Public Health UG Scholars who were trained for a week in sample selection procedures, interview techniques, and measurement of blood pressure and anthropometrics. The pilot test of the survey was done to check the feasibility of the study. The measurement of height and weight was done using standardized instruments. The digital weighing scale utilized was regularly compared against a standard weight. Waist measurements were done using non-stretchable measuring tapes. Blood pressure recordings were done using a digital sphygmomanometer with an adult-sized cuff. The weight measurements were done till nearest $0.1 \mathrm{~kg}$, height and waist till nearest $0.1 \mathrm{~cm}$ and blood pressure till nearest $1 \mathrm{mmHg}$. The pregnant women were excluded for the component of obesity measurement. The definitions used for various parameters were as per the WHO STEPS guidelines [9]. Current daily smokers were defined as those who were currently smoking cigarettes, bidis or hookah daily. Inadequate intake of fruits and vegetable was defined as consuming less than five servings in a day. A person was labelled as inactive if he/she was inactive in all the three domains of work, transport, and leisure. Raised blood pressure was defined as systolic blood pressure $>140 \mathrm{mmHg}$ and/or diastolic blood pressure $>90 \mathrm{mmHg}$ or under medication [11]. Body mass index (BMI) was calculated, and overweight was defined as BMI $>23 \mathrm{~kg} / \mathrm{m} 2$; abdominal obesity was diagnosed when waist circumference (WC) was $>90 \mathrm{~cm}$ in men and $>80 \mathrm{~cm}$ in women in accordance with the recommendations of World Health Organization for Asian adults [12]. For surveillance, mean levels of risk factors in the population serve as the best indicators of their status in the community. We also present results of the risk factors by selected cut-offs. However, different cut-offs have been recommended by different agencies at different times be it obesity, diabetes, hypertension etc. It may also be pointed out that the objective of the survey was not to assess the prevalence of diseases. Blood pressure levels reported in the survey are not true measures of prevalence of diabetes and hypertension, respectively.

\subsection{Statistical analysis}

To compare proportions and group, mean V2 test and student's t test were used, respectively. Analyses for the linear trend in proportions were done by Chi-square for trend using the STATCALC function in the Epi Info software [13]. 


\section{RESULTS AND DISCUSSION}

\subsection{Socio demographic characteristics}

A total of 394 government teachers participated in WHO STEPwise instrument survey. The socio demographic characteristics shows that the majority of the respondents were males $(n=294 ; 74.6 \%)$, both genders were prominently from the age-group of 45-54 years $(n=143,36.3 \%)$ and most of the respondents were married $(n=257,65.2 \%)$ as shown in Table 1 .

Table 1. Demographic characteristics of respondents

\begin{tabular}{cccc}
\hline \multicolumn{2}{c}{ Variables } & Frequency $(\mathrm{n}=394)$ & Percentage (\%) \\
\hline \multirow{3}{*}{ Gender } & Male & 100 & 25.4 \\
& Female & 294 & 74.6 \\
& Total & 394 & 100.0 \\
& Below 34 & 83 & 21.1 \\
Age & $35-44$ & 103 & 26.1 \\
& $45-54$ & 143 & 36.3 \\
& Above 55 & 65 & 16.5 \\
\multirow{5}{*}{ Marital status } & Total & 394 & 100.0 \\
& Unmarried & 137 & 34.8 \\
& Married & 257 & 65.2 \\
& Total & 394 & 100.0 \\
\hline
\end{tabular}

An illustrative association of hypertension and consumption of tobacco was calculated as shown in Table 2. Respondents who are hypertensive and not consume tobacco were $274(69.5 \%)$ as compared to 27 $(6.85 \%)$ of them who do not consume tobacco. The underlying difference is found to be of statistically significant $(\mathrm{p}<0.05)$. Among those hypertensive samples, those who do not consume alcohol are 283 (71.8\%), compared with on $18(4.7 \%)$ individuals who consume alcohol. This difference is statistically significant $(\mathrm{p}<0.05)$. BMI was calculated based on the respondents' height and weight, which identified that the individuals falling under the category of normal BMI ranges were 141 (35.78\%), overweight category were 109 (27.67\%), obese were 38 (9.64\%) and Underweight were $13(3.3 \%)$.

Table 2. Hypertension and modified risk factor concerning with BMI, tobacco and alcohol consumption

\begin{tabular}{|c|c|c|c|c|c|}
\hline \multicolumn{6}{|c|}{ Hypertension } \\
\hline Variables & Valid & $\begin{array}{c}\text { Yes } \\
\mathrm{n}(\%)\end{array}$ & $\begin{array}{c}\text { No } \\
\text { n (\%) }\end{array}$ & $\chi^{2}$ & p-value \\
\hline \multirow{2}{*}{ Consumption tobacco } & Yes & $27(6.85 \%)$ & $17(4.3 \%)$ & \multirow{2}{*}{6.207} & \multirow{2}{*}{$0.012<0.05$} \\
\hline & No & $274(69.5 \%)$ & $76(19.2 \%)$ & & \\
\hline \multirow{2}{*}{ Consumption alcohol } & Yes & $18(4.7 \%)$ & $13(3.3 \%)$ & \multirow{2}{*}{6.270} & \multirow{2}{*}{$0.013<0.05$} \\
\hline & No & $283(71.8 \%)$ & $80(20.3 \%)$ & & \\
\hline \multirow{4}{*}{ BMI } & Under weight & $13(3.3 \%)$ & $1(0.25 \%)$ & \multirow{4}{*}{9.570} & \multirow{4}{*}{$0.023<0.05$} \\
\hline & Normal weight & $141(35.78 \%)$ & $40(10.15 \%)$ & & \\
\hline & Over weight & $109(27.67 \%)$ & $29(7.36 \%)$ & & \\
\hline & Obesity & $38(9.64 \%)$ & $23(5.837 \%)$ & & \\
\hline
\end{tabular}

\subsection{Gender association with poor lifestyle}

As evident from Table 3, the smoking and consumption of alcohol rates $(\mathrm{p}<0.05)$ were significantly higher among men, whereas BMI ranges were significantly higher among female. The association between Gender and BMI, Consumption of tobacco and alcohol were calculated. 9.89\% males ( $\mathrm{n}=39)$ and $1.26 \%$ females $(n=5)$ out of the total respondents reportedly consumed tobacco and $7.36 \%$ males $(n=29)$ and $0.51 \%$ females $(n=2)$ consumed alcohol. These difference is statistically significant $(\mathrm{p}<0.05)$. Respondents who were underweight were $2.79 \%$ females $(n=11)$ and $0.76 \%$ males $(n=3)$; normal weight were $33.75 \%$ females $(n=133)$ and $12.18 \%$ females $(n=48)$; overweight were $25.12 \%$ females $(n=99)$ and $9.89 \%$ males $(n=39)$; obese were $12.94 \%$ females $(n=51)$ and $2.53 \%$ males $(n=10)$. These difference were also found to be statistically significant $(\mathrm{p}<0.05)$. 
Table 3. Association of modified risk factor concerning with BMI, tobacco, and alcohol consumption

\begin{tabular}{cccccc}
\hline \multirow{2}{*}{ Variables } & Valid & Male n $(\%)$ & Female n (\%) & $\chi^{2}$ & p-value \\
\hline \multirow{2}{*}{ Consumption tobacco } & Yes & $39(9.89 \%)$ & $5(1.26 \%)$ & & \\
& No & $61(15.5 \%)$ & $289(73.35 \%)$ & 104.646 & $0.000<0.05$ \\
Consumption alcohol & Yes & $29(7.36 \%)$ & $2(0.51 \%)$ & & \\
& No & $71(18.02 \%)$ & $292(74.11 \%)$ & 82.557 & $0.000<0.05$ \\
& Under weight & $3(0.76)$ & $11(2.79 \%)$ & & \\
& Normal weight & $48(12.18 \%)$ & $133(33.75 \%)$ & 3.445 & $0.328>0.05$ \\
& Over weight & $39(9.89 \%)$ & $99(25.12 \%)$ & & \\
\hline
\end{tabular}

\subsection{Diabetes with respect to relevant factor}

Diabetes remained one of the prominent NCDs. The essential diabetic management that was carried out by the participants were determined and reported in the below Table 4. Table 5 shows participant's awareness and perceptions towards health monitoring, i.e., testing their blood sugar levels, blood pressure in the case of hypertension and cholesterol levels in the case of obesity conditions. For all such variables, cooccurrences was determined via identifying Non-hypertensive and hypertensive individuals. $57.1 \%$ of respondents $(n=225)$ reported having measured their blood pressure. Table 6 shows alternative interventional approaches and dietary management undertaken by the respondents for coping with NCDs. This provided a generalized overview on how the sample population took efforts to combat NCDs.

Table 4. Management strategies on diabetes control

\begin{tabular}{cccccc}
\hline Variables & \multicolumn{3}{c}{ Diabetes } \\
& Valid & $\begin{array}{c}\text { Yes } \\
\mathrm{n}(\%)\end{array}$ & $\begin{array}{c}\text { No }(\%) \\
\text { Total }\end{array}$ & p-value \\
\hline \multirow{2}{*}{ Reduce sugary beverages in your diet } & Yes & $16(4 \%)$ & $58(14.7 \%)$ & 74 \\
& No & $28(7.1 \%)$ & $292(74.1 \%)$ & 320 & $0.003<0.05$ \\
& Total & 44 & 350 & 394 & \\
Eat at least 5 servings of fruits or vegetables each day & Yes & $21(5.32 \%)$ & $102(25.8 \%)$ & 123 & \\
& No & $23(5.8 \%)$ & $248(62.9 \%)$ & 271 & $0.011<0.05$ \\
& Total & 44 & 350 & 394 & \\
\hline
\end{tabular}

Table 5. Ever measured NCD with respect to hypertension

\begin{tabular}{|c|c|c|c|c|c|}
\hline \multirow[b]{2}{*}{ Variables } & \multicolumn{4}{|c|}{ Hypertension } & \multirow[b]{2}{*}{ p-value } \\
\hline & Valid & $\begin{array}{l}\text { Non-hypertensive } \\
\mathrm{n} \%\end{array}$ & $\begin{array}{c}\text { Hypertensive } \\
\mathrm{n} \%\end{array}$ & Total & \\
\hline \multirow{4}{*}{ Ever measured blood sugar } & Yes & $225(57.1 \%)$ & $63(16 \%)$ & 288 & \multirow{3}{*}{$0.116>0.05$} \\
\hline & No & $76(19.2 \%)$ & $30(7.6 \%)$ & 106 & \\
\hline & Total & 301 & 93 & 394 & \\
\hline & Yes & $68(17.2 \%)$ & $34(8.6 \%)$ & 102 & \multirow{3}{*}{$0.003<0.05$} \\
\hline \multirow[t]{2}{*}{ Ever measured for hypertension } & No & $233(59.1 \%)$ & $59(60 \%)$ & 292 & \\
\hline & Total & 301 & 93 & 394 & \\
\hline \multirow{3}{*}{$\begin{array}{c}\text { Ever measured } \\
\text { cholesterol }\end{array}$} & Yes & $32(8 \%)$ & $22(5.5 \%)$ & 54 & \multirow{3}{*}{$0.002<0.05$} \\
\hline & No & $269(68.2 \%)$ & $71(18.0 \%)$ & 340 & \\
\hline & Total & 301 & 93 & 394 & \\
\hline
\end{tabular}

Table 6. Alternative interventional and dietary management for combating NCDs

\begin{tabular}{lccc}
\hline Alternative interventional approaches/Dietary management & Yes & No & Total \\
\hline Traditional healer for diabetes & $10(2.5 \%)$ & $384(97.5 \%)$ & $394(100 \%)$ \\
Traditional healer for high blood pressure & $58(14.7 \%)$ & $336(85.3 \%)$ & $394(100 \%)$ \\
Ever seen a traditional healer for high cholesterol & $11(2.8 \%)$ & $383(97.2 \%)$ & $394(100 \%)$ \\
5 servings of fruits or vegetables each day & $123(31.2 \%)$ & $271(68.8 \%)$ & $394(100 \%)$ \\
Too much salt causes health problems & $329(83.5 \%)$ & $65(16.5 \%)$ & $394(100 \%)$ \\
Start or do more physical activity & $93(23.6 \%)$ & $301(76.4 \%)$ & $394(100 \%)$ \\
Reduce salt in your diet & $122(31.0 \%)$ & $272(69.0 \%)$ & $394(100 \%)$ \\
Reduce fats in your diets & $93(23.6 \%)$ & $301(76.4 \%)$ & $394(100 \%)$ \\
Reduce sugary beverages in your diet & $74(18.8 \%)$ & $320(81.2 \%)$ & $394(100 \%)$ \\
\hline
\end{tabular}

NCDs pose public health related issues on a global scale, a concern that has been raised time and again by many international organizations and welfare programs like WHO and CDC. The growing prevalence and morbidity among the adult populations, serving as a prominent factor for senile deaths is a cause of concern [14], [15]. Regulating the increasing burden of NCDs in low and middle-income countries 
involves establishing adequate systems for monitoring the same and using the data obtained to upgrade or implement control strategies [16]. This paper shows NCDs impact among the study population who are falling under category of literates, whose profession is primary government teacher in Jodhpur. We also noted awareness perception/practice mismatch regarding dietary sugar and salt as NCD risk factors and so forth. The survey respondents were generally middle-aged and majority were males, most likely due to the fact that this was based survey on the basis of profession and predominantly men are the most consistent and commonly available participants especially among primary schools and were subjected to study in accordance to Indian context [17].

It was observed that more than a fifth of the respondents reported poor lifestyle high dietary salt intake. Regardless of other factors, lifestyle oriented disorders could serve as a possible burden/ risk factor for etiologies concerned with NCDs [18], [19]. Approximately it was observed that only $<5 \%$ of the respondents reported with alcohol and tobacco consumption. BMI attribute for numerous complication. In our present study, high BMI ranges results primly in obesity and could serve indirectly serve as a major risk factor for diabetes and hypertension as well [20]. From the survey it was found that participants belonging under overweight category of 109(27.67\%) was higher and there is a greater likelihood among the participants with no NCDs could more likely could acquire health associated complications due to their poor BMI levels in the near future [21], [22].

Co-occurrences are often observed in NCD cases. This is predominantly due to their direct association with one another, alongside with common risk factors [23]. This is comparable with the findings of Subasinghe et al. (2014) with hypertension through meta-analysis that found association of high salt intake of $21 \%$ to $90 \%$, as well as a meta-analysis of other studies from the continent on salt intake, done in 2016 [24], [25]. Discretionary salt intake (salt addition at the table) is a major contributor to high salt intake globally; however it is difficult to control in a wide scale through legislation. The contribution of salt intake from processed foods is relatively less in low-to-middle-income country (LMICs) but could be on the rise due to urbanization and changes in lifestyles, with urban residents frequently preferring processed fast foods. Salt intake control strategies generally are two pronged; reduction of salt in processed foods through legislation to govern the food industry as well as enforcement of existing laws, and secondly, creating consumer awareness and public education, especially to combat discretionary excessive salt intake.

Regardless of other factors, lifestyle oriented disorders could serve as a possible burden/risk factor for etiologies concerned with NCDs [18], [19]. Approximately it was observed that only <5\% of the respondents reported with alcohol and tobacco consumption. BMI attribute for numerous complication. In our present study, high BMI ranges results primly in obesity and could serve indirectly serve as a major risk factor for diabetes and hypertension as well [26]. From the survey it was found that participants belonging under overweight category of $109(27.67 \%)$ was higher and there is a greater likelihood among the participants with no NCDs could more likely could acquire health associated complications due to their poor BMI levels in the near future [14].

High dietary sugar intake is associated with several health hazards including insulin resistance and subsequently type 2 diabetes, abnormal lipids, hypertension, obesity and several other cardio-metabolic risk factors [27]. The observed mismatch between awareness and practice on health hazards of high dietary salt and sugar intake has been observed in other nutritional surveys in different settings [28], [29]. From the current understanding pertaining to our research it could be hypothesized over the very explanation of the underlying mismatch as majority population lack knowledge on measures to reduce dietary sugar and salt intake, even though they are aware of the health hazards.

Only minimal degree of participants reported consuming the minimum daily recommended fruits and vegetables. Low fruit and vegetable intakes have also been noted in other STEPS surveys whose findings have been reported to the WHO [30]. Association between unhealthy diet with male gender and age has been noted from studies [28], [31] This is likely due to increase in rural-urban migration for career opportunities among the youth and adoption of diets high in processed foods from restaurants and fast food as a consequence of rapid urbanization. There was a high percentage of teachers taking traditional medicines for hypertension and diabetes and only $5 \%$ of the affected teachers were taking allopathic medications. As only $31 \%$ were taking five servings of fruits and vegetables in their daily diet there was a need to sensitize them about balance diet. Health education regarding post 35 years periodic self - monitoring of blood sugar, blood pressure and cholesterol/lipid profile and need for regular vigorous activity was found to be the need of the hour.

\section{CONCLUSION}

From this survey it could be inferred that there is still some insignificancies considering with individuals perception and awareness on NCDs and its associated risk factors. Also it could be inferred that there is a high degree of participants with poor lifestyle and are not cautious with their health. The need for 
regular monitoring of blood sugar, blood pressure and BMI is essential for preventing or even slowing the overall degree of NCDs impact in their physical and mental health. This survey assessed baseline levels by identifying the overall prevalence and associated risk factors which provided first step towards initiating surveillance for NCDs among school teachers in Jodhpur, Rajasthan, whilst delivering the necessary information concerning with developing a suitable framework for determining priorities over intervention.

\section{ACKNOWLEDGEMENTS}

Authors acknowledge all the Public Health undergraduate scholars who have helped in data collection for this study. We are also thankful to the participants and schools as this study would not have been possible without their support and assistance.

\section{REFERENCES}

[1] NK. Joshi, YK Jain, V. Joshi, J. Sharma, N. Kumar, and P. Bhardwaj, "Assessment of Health-Related Quality of Life among NCD patients," International Journal Public Health Science (IJPHS), vol. 10, no. 4, 2021, doi: 10.11591/ijphs.v10i4.20961

[2] S. Seshadr and V. Hebbare, "Benefit-Cost Analysis Non-Communicable Diseases. Rajasthan Priorities, Copenhagen Consensus Center. License: Creative Commons Attribution CC BY 4.0;; 2017 [Online]. Available: https://www.copenhagenconsensus.com/sites/default/files/raj_ncd_fomatted_sm.pdf

[3] K. Paul and J. Singh, "Emerging trends and patterns of self-reported morbidity in India: Evidence from three rounds of national sample survey," J Health Popul Nutr., vol. 36, no. 1, pp. 1-13, 2017, doi: 10.1186/s41043-0170109-x.

[4] N. Das and R. Kumar, "Role of Non-Governmental Organizations in Healthcare Sector in India," Public Health Foundation of India (PHFI), Delhi. 2016. [Online]. Available: 2016 Online at https://mpra.ub.uni-muenchen.de/79402/

[5] N. Garin et al., "Global Multimorbidity Patterns: A Cross-Sectional, Population-Based, Multi-Country Study," J Gerontol A Biol Sci Med Sci., vol. 71, no. 2, pp. 205-214, 2016, doi: 10.1093/gerona/glv128.

[6] K. Saravanan and K. Muthu Lakshmi, "A Study on Occupational Stress among Teachers of Higher Secondary Schools in Nagappattinam District," Journal of Teacher Education and Research, vol. 12, no. 2, pp. 144-156, 2017, doi: 10.5958/2454-1664.2017.00017.9.

[7] L. Hegarty, MH. Murphy, K. Kirby, E. Murtagh, J. Mallett, and JL. Mair, "The Influence of Role Models on the Sedentary Behaviour Patterns of Primary School-Aged Children and Associations with Psychosocial Aspects of Health," Int J Environ Res Public Health. vol. 17, no. 15, pp. 1-11, 2020, doi: 10.3390/ijerph17155345.

[8] YK. Jain, NK. Joshi, P. Bhardwaj, P. Suthar, "Health-promoting school in India: Approaches and challenges," $J$ Family Med Prim Care. vol. 8, no. 10, pp. 3114-3119, 2019, doi: 10.4103/jfmpc.jfmpc_673_19.

[9] World Health Organization, "WHO STEPS Surveillance Manual," WHO, 2017, [Online]. Available: https://www.who.int/ncds/surveillance/steps/STEPS_Manual.pdf?ua=1.

[10] World Health Organization, "Noncommunicable Diseases and Mental Health Cluster. WHO STEPS surveillance manual: the WHO STEPwise approach to chronic disease risk factor surveillance/Noncommunicable Diseases and Mental Health, World Health Organization," World Health Organization, 2005, [Online] Available: https://apps.who.int/iris/handle/10665/43376

[11] Cdc.gov, "High Blood Pressure Symptoms, Causes, and Problems," CDC; 2021, [Online]. Available: https://www.cdc.gov/bloodpressure/about.htm.

[12] M. Verma, M. Rajput, K. Kishore, and S. Kathirvel, "Asian BMI criteria are better than WHO criteria in predicting Hypertension: A cross-sectional study from rural India," J Family Med Prim Care, vol. 8, vol. 6, pp. 2095-2100, 2019, doi: 10.4103/jfmpc.jfmpc_257_19.

[13] Cdc.gov., "Epi Info ${ }^{\mathrm{TM}}$ CDC," cited 17 February 2020, [Online] Available: https://www.cdc.gov/epiinfo/index.html

[14] World Health Organization, "GLOBAL STATUS REPORT on noncommunicable diseases 2014," Switzerland: WHO; 2014, [Online]. Available: https://apps.who.int/iris/bitstream/handle/10665/148114/9789241564854_eng.pdf?sequence=1.

[15] N. B.Johnson, L.D. Hayes, K. Brown, E. C Hoo, K. A Ethier, Centers for Disease Control and Prevention (CDC) "CDC National Health Report: Leading Causes of Morbidity and Mortality and Associated Behavioral Risk and Protective Factors-United States, 2005-2013," MMWR Morb Mortal Wkly Rep, vol. 63, no. 4, pp. 23-27, 2014.

[16] S. Nethan, D. Sinha, and R. Mehrotra, "Non-Communicable Disease Risk Factors and their Trends in India," Asian Pac J Cancer Prev., vol. 18, no. 7, pp. 2005-2010, 2017, doi: 10.22034/APJCP.2017.18.7.2005.

[17] K. Tremblay, D. Lalancette, and D. Roseveare, "AHELO Feasibility Study Report," OECD; 2012, [Online]. Available: http://www.oecd.org/education/skills-beyond-school/AHELOFSReportVolume1.pdf.

[18] R. Peters et al., "Common risk factors for major noncommunicable disease, a systematic overview of reviews and commentary: the implied potential for targeted risk reduction," Ther Adv Chronic Dis., vol. 10, pp. 1-14, 2019, doi: $10.1177 / 2040622319880392$.

[19] A. Mujezinović, L. Čalkić, N. Hasanica, and S. Tandir, "Tobacco and alcohol usage as risk factors of noncommunicable diseases among students of Zenica University (Bosnia and Herzegovina)," Med Glas (Zenica), vol. 15, no. 1, pp. 81-86, 2018, doi: 10.17392/933-18. 
[20] L. Webber et al., "The future burden of obesity-related diseases in the 53 WHO European-Region countries and the impact of effective interventions: a modelling study," BMJ Open, vol. 4, pp. 1-8, 2014, doi: 10.1136/bmjopen2014-004787.

[21] D. Segula, "Complications of obesity in adults: a short review of the literature," Malawi Med J., vol. 26, no. 1, pp. 20-24, 2014

[22] WHO, "Obesity and overweight," who.int. 2020. [Online]. Available from: https://www.who.int/news-room/factsheets/detail/obesity-and-overweight.

[23] S. Khare and D. Gupta, "Association rule analysis in cardiovascular disease," 2016 Second International Conference on Cognitive Computing and Information Processing (CCIP), Mysore, 2016, pp. 1-6, doi: 10.1109/CCIP.2016.7802881.

[24] AK. Subasinghe et al., "Association between salt and hypertension in rural and urban populations of low to middle income countries: a systematic review and meta-analysis of population-based studies," Asia Pac J Clin Nutr., vol. 25, no. 2, pp. 402-413, 2016, doi: 10.6133/apjen.2016.25.2.25.

[25] JR. Nansseu et al., "The highly neglected burden of resistant hypertension in Africa: a systematic review and metaanalysis," BMJ Open, vol. 6, no. 9, 2016, doi: 10.1136/bmjopen-2016-011452.

[26] L. Webber et al., "The future burden of obesity-related diseases in the 53 WHO European-Region countries and the impact of effective interventions: a modelling study," BMJ Open, vol. 4, no. 7, pp. 1-9, 2014, doi: 10.1136/bmjopen-2014-004787.

[27] JJ. DiNicolantonio, "Lucan SCThe wrong white crystals: not salt but sugar as aetiological in hypertension and cardiometabolic disease,"Open Heart, vol. 1, no. 1, 2014, doi: 10.1136/openhrt-2014-000167.

[28] P. Magalhães, EJ. Sanhangala, IM. Dombele, HS. Ulundo, DP. Capingana, and AB. Silva, "Knowledge, attitude and behaviour regarding dietary salt intake among medical students in Angola," Cardiovasc J Afr., vol. 26, no. 2, pp. 57-62, 2015, doi: 10.5830/CVJA-2015-018.

[29] CA. Grimes, LJ. Riddell, KJ. Campbell, and CA. Nowson, "Dietary salt intake, sugar-sweetened beverage consumption, and obesity risk," Pediatrics, vol. 131, no. 1, pp. 14-21, 2013, doi: 10.1542/peds.2012-1628.

[30] K. Aryal et al., "The Burden and Determinants of Non-Communicable Diseases Risk Factors in Nepal: Findings from a Nationwide STEPS Survey," PLoS ONE, vol. 10, no. 8, pp. 1-18, 2015, doi: 10.1371/journal.pone.0134834.

[31] G. Eksteen, "Salt intake in South Africa: a current perspective: guest editorial," Journal of Endocrinology, Metabolism and Diabetes in South Africa, vol. 20, no. 1, pp. 9-14, 2015. 